\title{
Practice of community-service doctors in the assessment and medico-legal documentation of common physical assault cases
}

\author{
L Fouchéa, J Bezuidenhout ${ }^{\mathrm{a}}, \mathrm{C}$ Liebenberg $^{\mathrm{b}}$ and AO Adefuye ${ }^{\mathrm{a}^{*}}$ (ID
}

${ }^{a}$ Division of Health Sciences Education, Faculty of Health Sciences, University of the Free State, Bloemfontein, South Africa

${ }^{b}$ Department of Forensic Medicine, School of Medicine, Faculty of Health Sciences, University of the Free State, Bloemfontein, South Africa

*Corresponding author, email:AdefuyeAO@ufs.ac.za

Background: In South Africa, allegations of physical assault are managed primarily at the primary healthcare level, where they are attended to by medical officers or community service doctors (CSDs). However, reports that the knowledge and skills provided at undergraduate level are not sufficient to equip these CSDs to deal with evidence in medico-legal examinations in various settings, including in cases of patients who allege being the victims of common physical assault or assault with intent to inflict grievous bodily harm, have been documented in the literature. This study investigates the practice of CSDs in relation to the assessment and medico-legal documentation of allegations of common assault, with a view to identifying gaps in their knowledge of clinical forensic medicine.

Method: The study was a cross-sectional descriptive study. A questionnaire with quantitative sections that used an adapted Likert scale was used to gather data. An electronic survey tool was employed to target 150 CSDs countrywide. Percentages are used to display results.

Results: A response rate of $59.3 \%$ was achieved and results indicate that clinical forensic training in the undergraduate medical programme does not prepare CSDs sufficiently for the task of managing the medico-legal examination and documentation of allegations of assault by patients.

Conclusions: The courts rely heavily on medico-legal documentation for success in criminal prosecution. Any substantial flaw in the documentation, including inadequate observations and/or notes made by a medical practitioner, may make proving guilt very difficult. This study revealed an important gap in the knowledge and practice of clinical forensic medicine by CSDs and suggests that the current curriculum should be adapted to allow adequate training of undergraduate medical students in the area of clinical forensic medicine. Appropriate undergraduate training will ensure that medico-legal documentation is completed accurately and that medical practitioners help ensure the administration of justice.

Keywords: assault, clinical forensic medicine and curriculum, medico-legal documentation

\section{Introduction}

According to South African law the integrity of the physical person (corpus), dignity of the person (dignitas), and the reputation (fama) of the person are the trinity of interests of human personality protected by criminal sanction. ${ }^{1}$ While violations of fama and dignitas are prosecuted as defamation and crimen injuria respectively, violation of the interest in corpus is prosecuted as assault. ' South Africa (SA) has one of the highest rates of incidence of interpersonal violence, including indecent assault, in the world. ${ }^{2,3}$ According to the $2015 / 2016$ crime statistics of the South African Police Service (SAPS) a total of 164,958 and 182,933 counts of common assault and assault with intent to inflict grievous bodily harm, respectively, were recorded between April 1, 2015 and March 31, 2016. ${ }^{4}$ Members of the SAPS and the medical fraternity share the responsibility of ensuring successful conviction and accurate administration of justice by presenting relevant medical forensic evidence to advance informed decisions on legal matters. ${ }^{5}$ Medical evidence is often crucial for proving a case and obtaining a conviction. However, in spite of improved awareness and service upgrades, the conviction rate of people charged with assault in SA is disappointingly low compared with other countries. ${ }^{2}$ This fact can be attributed to, among others, errors made by clinicians in the broad field of forensic medicine. ${ }^{6}$ The difference between a conventional clinical examination, aimed at diagnosing the cause of a disease, and a medico-legal/forensic examination of a victim, which is expected to provide additional information that may have important legal rather than medical connotations, is often poorly understood by doctors. ${ }^{2,6}$
In SA, allegations of physical assault are managed primarily at primary healthcare level, ${ }^{5}$ where they are attended to by medical officers or CSDs. It has been reported that the knowledge and skills provided at undergraduate level are not sufficient to equip medical graduates to deal with clinical forensic cases. ${ }^{5}$ Hence, the aim of this study was to assess the practice of CSDs in relation to the assessment and medico-legal documentation of patients who report being assaulted, with a view to identifying gaps in the CSDs' knowledge of the practice of clinical forensic medicine.

\section{Methods}

A cross-sectional descriptive study was done of 150 CSDs who were medical graduates of the School of Medicine, Faculty of Health Sciences, University of the Free State (2005-2007), and who had either completed their community service or were still in service at the time of the study. A comprehensive list of names was obtained from the administration of the Faculty of Health Sciences from which the prospective participants had graduated $(n=300)$. A non-random sampling was used as all 300 prospective participants were included in the study. The contact details of all prospective participants ( $n=$ 300) was sourced from the Health Professions Council of South Africa. However, after a follow-up only 150 CSDs of the total 300 prospective participants had active telephone contacts and gave consent to participate in the study. The remaining 150 prospective participants either did not have active telephone contacts or did not respond to voicemail messages. Each non-responder was phoned at least twice. All potential participants were contacted telephonically to obtain verbal consent to participate in the study. 
A self-administered questionnaire was used to obtain the sincere responses of the participants. The questionnaire was available in Afrikaans and English and was dispatched electronically via email. The questionnaire was divided into four parts: demographics (age, gender and home language); professional profile; employment profile (when and where participants performed their community service); competency in medico-legal assessment and documentation of assault cases during the service year. A three-point Likert scale was used (Yes always, Yes, sometimes, and No). The response rate was $59.3 \%$ (89 of the initial 150 questionnaires that were distributed were returned) despite numerous (email and text messages) reminders sent to all the participants at intervals. The results were captured on Microsoft Excel ${ }^{\oplus} 2013$ (Microsoft Corp, Redmond, WA, USA), and analysed by a biostatistician from the Department of Biostatistics, University of the Free State.

Ethical clearance was received from the Ethics Committee of the Faculty of Health Sciences at the University of the Free State (HSREC 149/2011), the acting head of the School of Medicine, and the vicerector: Academic Planning at the University of the Free State.

\section{Results}

\section{Demographic information}

In the study sample of 89 participants, $76.2 \%(n=67)$ were in the 27-29 years age group. The gender distribution was $61.8 \%$ women and 38.2\% men. Among the participants, 73\% ( $n=65)$ reported Afrikaans as their first language, and $15.7 \%(n=14)$ reported English as their first language, whilst $11.2 \%(n=10)$ reported other languages as their first language.

In terms of placement, $39.3 \%(n=35)$ and $1.1 \%(n=1)$ of the participants did their community service in the Free State and Limpopo provinces, respectively (Table 1). Furthermore, $47.2 \%$ of

Table 1: Demographic characteristics of participants who responded to the questionnaire

\begin{tabular}{lc}
\hline Characteristics & $\%(\boldsymbol{n})$ \\
\hline Age $(n=88)$ & $76.2(67)$ \\
\hline $27-29$ & $17(15)$ \\
\hline $30-32$ & $6.8(6)$ \\
\hline $33+$ & \\
\hline Gender ( $=89)$ & $38.2(34)$ \\
\hline Male & $61.8(55)$ \\
\hline Female & \\
\hline First language $(n=89)$ & $73(65)$ \\
\hline Afrikaans & $15.7(14)$ \\
\hline English & $11.2(10)$ \\
\hline Others (Zulu, Xhosa, Sotho etc.) & \\
\hline Province of service $(n=89)$ & $7.9(7)$ \\
\hline Western Cape & $10.1(9)$ \\
\hline Eastern Cape & $12.4(11)$ \\
\hline Northern Cape & $13.5(12)$ \\
\hline North-West & $6.7(6)$ \\
\hline Gauteng & $5.6(5)$ \\
\hline Mpumalanga & $1.1(1)$ \\
\hline Limpopo & $39.3(35)$ \\
\hline Free State & $3.4(3)$ \\
\hline KwaZulu-Natal & \\
\hline
\end{tabular}

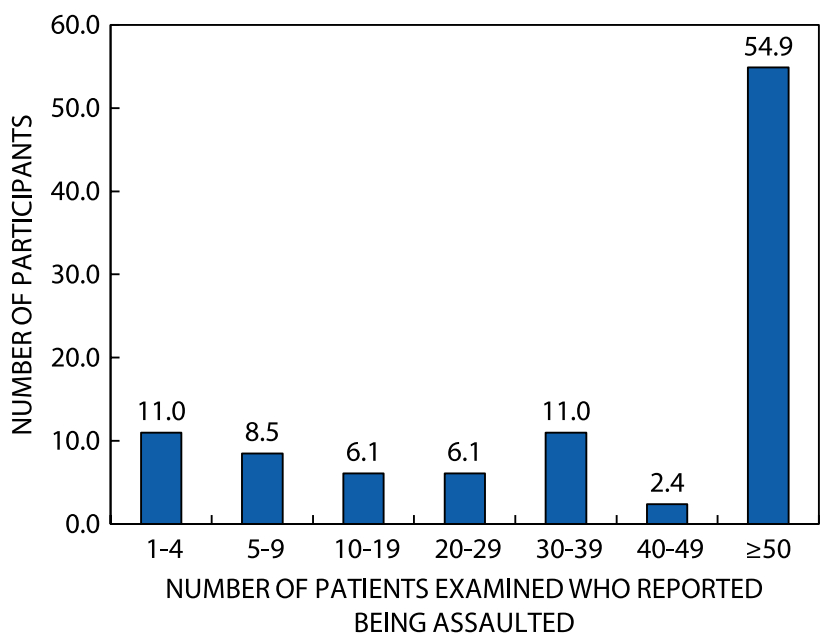

Figure 1: Number of examinations conducted on patients who reported being assaulted $(n=82)$.

the participants completed their service in urban communities, $27.9 \%$ of them served in a mixed urban-rural community, whilst a minority of participants (25.8\%) did their community service in a rural setting.

\section{Patients encountered during year of community service who reported having been assaulted}

Participants were asked whether, during the period of their community service, they had examined any patient who had reported being physically assaulted. The majority $(93.2 \%, n=82)$ of participants said they had examined such patients in their year of community service, while $6.8 \%(n=6)$ of participants had never examined patients who had claimed to be assaulted (one participant did not answer the question). Furthermore, when asked how many patients claiming to have been assaulted they had examined, the majority of participants $(54.9 \%, n=45)$ reported having examined 50 cases or more in the one-year period (Figure 1).

\section{Collecting and documenting relevant history concerning alleged assaults}

The J88 form is a legal document used to record the factual findings of a medical assessment of a patient, and the opinion of the medical practitioner regarding the significance of the facts. Therefore, it is mandatory that the J88 form be completed by a medical practitioner for every patient who presents to a health facility and reports being assaulted. When participants were asked whether the $J 88$ form accompanied patients reporting being assaulted, only $18.5 \%$ of participants who had encountered such patients reported that the J88 form always accompanied the patient, $76.5 \%$ reported that the $\mathbf{J} 88$ form sometimes accompanied the patient, and $5 \%$ of the participants said the patients were not accompanied by the form (Table 2).

Furthermore, when asked about taking relevant history, $82.5 \%$ of the participants attested to always taking relevant history; $81.5 \%$ of the participants reported that they always documented the relevant history on the J88 form (see Table 2). Docket analysis has shown that a large number of alleged assaults are associated with consumption of alcohol or other addictive substances. ${ }^{4}$ Hence, it is important to take the history of alcohol consumption. In this study, $60.8 \%$ of participants who indicated that they had examined patients reporting being assaulted always asked the patient about alcohol usage, whereas $36.7 \%$ of participants 
Table 2: Participants' responses regarding history taking and documentation for the J88 form

\begin{tabular}{lccc}
\hline Item & Yes, always \% $(\boldsymbol{n})$ & $\begin{array}{c}\text { Yes, sometimes } \\
\%(\boldsymbol{n})\end{array}$ & No \% (n) \\
\hline $\begin{array}{l}\text { J88 accompanied } \\
\text { the patient }(n=81)\end{array}$ & $18.5(15)$ & $76.5(62)$ & $5.0(4)$ \\
$\begin{array}{l}\text { Took relevant histo- } \\
\text { ry about the alleged } \\
\text { assault }(n=80)\end{array}$ & $82.5(66)$ & $17.5(14)$ & $0(0)$ \\
$\begin{array}{l}\text { Noted the relevant } \\
\text { history on the J88 } \\
(n=81)\end{array}$ & $81.5(66)$ & $18.5(15)$ & $0(0)$ \\
$\begin{array}{l}\text { Asked about alco- } \\
\text { hol usage }(n=79)\end{array}$ & $60.8(48)$ & $36.7(29)$ & $2.5(2)$ \\
$\begin{array}{l}\text { Noted alcohol us- } \\
\text { age on J88 }(n=81)\end{array}$ & $63(51)$ & $33.3(27)$ & $3.7(3)$ \\
\hline
\end{tabular}

sometimes asked, and $2.5 \%$ of the participants never asked the patient about his/her alcohol usage (see Table 2). Of the participants who reported examining patients who reported being assaulted, $63 \%$ indicated that they documented history of alcohol usage on the $\mathrm{J} 88$ form, whereas $33.3 \%$ of the participants sometimes documented history of alcohol usage on the J88 form while $3.7 \%$ of participants did not (see Table 2 ).

\section{Examination, description and documentation of wounds and injuries}

During a medico-legal examination of a patient who reported having been assaulted, technically accurate use of wound terminology is very important for future legal proceedings as it enables precise identification of a weapon used in an assault or that caused an injury.

A bruise is a focal discolouration of the skin due to rupture of the small venules, with extravasation of the blood into the surrounding tissue due to blunt trauma. ${ }^{7}$ An abrasion is the loss of the superficial skin layers due to tangential blunt force trauma. ${ }^{7}$ Responses in the questionnaire of this study indicated that only $91.4 \%$ of participants who indicated that they had examined patients claiming to have been assaulted are able to recognise a bruise, and $96.3 \%$ are able to recognise an abrasion (Table 3), suggesting that seven (8.6\%) and three (3.7\%)

Table 3: Knowledge of participants in relation to examination, description and documentation of wounds and injuries $(n=81)$

\begin{tabular}{lccc}
\hline Factor & Yes, always \% (n) & $\begin{array}{c}\text { Yes, sometimes } \\
\%(\boldsymbol{n})\end{array}$ & No \% (n) \\
\hline $\begin{array}{l}\text { Identifying a bruise } \\
\begin{array}{l}\text { Identifying an } \\
\text { abrasion }\end{array}\end{array}$ & $91.4(74)$ & $*$ & $8.6(7)$ \\
$\begin{array}{l}\text { Identifying a } \\
\text { laceration }\end{array}$ & $98.8(80)$ & $*$ & $3.7(3)$ \\
$\begin{array}{l}\text { Identifying an } \\
\text { incised wound }\end{array}$ & $84(68)$ & $* 2(1)$ & $16(13)$ \\
$\begin{array}{l}\text { Measuring the } \\
\text { wound }\end{array}$ & $38.3(31)$ & $44.4(36)$ & $17.3(14)$ \\
$\begin{array}{l}\text { Noting the shape } \\
\text { of the wound } \\
\text { Documenting the } \\
\text { wounds on the J88 } \\
\text { form }\end{array}$ & $58(47)$ & $37(30)$ & $5(4)$ \\
\hline *Indicates that the option & $97.5(79)$ & $2.5(2)$ & $0(0)$ \\
\hline
\end{tabular}

*Indicates that the option was not available for that particular question. participants were unable to recognise a bruise and an abrasion, respectively.

A laceration is a full-thickness forceful tearing of the skin, with ragged edges, tissue bridges and hair and foreign material in the depths of the wound. ${ }^{7}$ Almost all the participants (98.8\%) who indicated that they had examined patients reporting being assaulted are able to recognise lacerations (see Table 3 ). In contrast to a laceration, an incised wound can be a slash wound, a cut wound or a stab wound. It is caused by sharp trauma with, for example, a knife. The wound edges are sharp and there are no tissue bridges, hair or foreign material in the depths of the wound. When asked whether they would recognise an incised wound, $84 \%$ of participants who indicated that they had examined patients who reported being assaulted indicated that they would be able to recognise an incised wound (see Table 3).

It is also mandatory that wounds and injuries are described individually in terms of location, type, size and shape, degree of severity and age. ${ }^{7}$ Thus, when the participants who indicated that they had examined patients who reported having been assaulted were asked if they had measured the wounds $38.3 \%$ of participants reported that they always measure wounds, $44.4 \%$ sometimes measured wounds, and $17.3 \%$ never measured wounds. Furthermore, only $58 \%$ of participants who had examined patients who reported having been assaulted during the participants' year of service reported always noting the shape of the wound, whereas 37\% sometimes did and 5\% never noted the shape of the wound (see Table 3). When asked if they documented the details of wounds on the J88 form, most of the participants (97.5\%) who indicated that they had examined patients who reported having been assaulted attested to always documenting the wounds on the J88 form; the remaining $2.5 \%$ sometimes documented the wounds (see Table 3).

\section{Undergraduate training and exposure to medico- legal documentation of assault cases}

Analysed data presented here reveal that only $66.7 \%$ of participants who indicated that they had examined assault cases during their year of community service had prior training and/or exposure to medico-legal documentation and management of assault cases during their undergraduate training. In addition, 70.4\% of the respondent CSDs indicated that they had undergraduate training on the documentation of wounds as regards assault cases. However, when asked if the respondent CSDs received any undergraduate training on completing the J88 form for assault cases, only $26.8 \%$ of participants indicated that they have received training while the majority of the CSDs (73.2\%) had never received any undergraduate training on completing the J88 form.

\section{Discussion}

In post-apartheid $\mathrm{SA}$, crime is one of the most serious challenges facing the country-it is claimed that SA has one of the highest crime rates in the world. ${ }^{8}$ The effect of the high crime rate extends beyond the pain or loss suffered by the victims, as it also has a direct cost impact on the economy. ${ }^{8}$ In SA, various forms of interpersonal violence are common, ranging from slapping, threatening to beat, hitting with sticks or other objects, pushing and assaulting with fists, to stabbing with a knife and shooting. ${ }^{9}$ Community assault (severe beating of an alleged criminal by members of the local community) has also been shown to be widespread in the townships of South Africa, ${ }^{10}$ and generally involves the use of a sjambok (a heavy leather whip traditionally 
made from an adult hippopotamus or rhinoceros hide) to inflict extensive soft-tissue trauma. ${ }^{10}$ Circumstantial evidence suggests that victims of community assault are more severely injured than their non-community assault counterparts. ${ }^{10}$

Forensic medicine is a specialty discipline that links medicine and law. It facilitates and influences legal cases by providing evidence in the form of documentation-the more thorough and robust the evidence contained in the documentation, the more useful it is in the legal process. ${ }^{11}$ In SA, efforts are being made to improve the practice of forensic medicine through the introduction of new training initiatives, such as the postgraduate diploma qualification developed by the University of the Free State..$^{5,12}$ However, knowledge and skills provided at undergraduate level are not sufficient to equip medical graduates to deal with clinical forensics cases. Hence, this study assesses the practice of medical graduates who, during their community service year, dealt with medico-legal documentation of patients who reported having been physically assaulted, with a view to identifying knowledge gaps in the undergraduate clinical forensic medicine curriculum.

In Pistorius v. The State (253/2013) [2014] ZASCA 47 (April 1, 2014), the Supreme Court of Appeal heard an appeal against a conviction on the basis of crimen injuria (along with an appeal against a conviction for assault with intent to commit grievous bodily harm). The complainant held that the following event occurred on the day of incident (at Paragraph [7]). ${ }^{13,14}$

The complainant went to report the incident to the police at the Vaal Police Station the same day. He subsequently consulted with $\mathrm{Dr}^{\prime} \mathrm{N}$ '. He testified that he was injured on his back and left arm. Furthermore, he explained that he had swollen and open wounds which were sutured and he was given some medication. He confirmed that he received a J88 form from the police, which he handed over to the police officer after the doctor had completed it as well as a sick note which he gave to his employers. He did not know what the police had done with the J88.

The J88 form is a legal form of the Department of Justice specifically designed to document relevant medical findings for court; it is broadly used in most clinical forensic examinations in SA. Findings as reported by the participants in this study reveal that, in most cases $(76.5 \%)$, a patient reporting being assaulted was not accompanied by the $J 88$ form when he/she presented at the healthcare facility. Although clinical notes can also be presented as evidence in medico-legal cases, a fully completed, legible J88 form with a well-formulated conclusion may be the only irrefutable evidence accepted by the court of law. It is the responsibility of the attending medical practitioner to complete the J88 form with the most relevant information, and to omit irrelevant information. ${ }^{15}$ The J88 form may only be handed over to a police official, and it is not supposed to be released to the patient (as seen in quote above from Pistorius v. The State), as this would compromise the chain of evidence and may render the evidence on the form inadmissible. ${ }^{5}$

In this study, some participants reported that they do not always take or document a relevant history (see Table 2), although this step is an essential part of a forensic medical examination. Failure to comprehensively take and document a relevant history can make the evidence untenable in court. Information given by the patient must be true, and an omission on the medical practitioner's part should not have an influence on the factual content. According to the SAPS, most reported instances of alleged assault occur in bars, taverns and shebeens (an unlicensed establishment or private house selling alcohol) while people are consuming alcohol. This was supported by findings for the Free State, in which alcohol played a role in $29 \%$ of recorded common assault cases. ${ }^{4}$ Only $60.8 \%$ and $63 \%$ of the participants in this study reported always taking and documenting the history of alcohol consumption respectively. A history of alcohol consumption is important, as it has been reported that at least a half of all violent crimes involve alcohol consumption by the perpetrator, the victim, or both. ${ }^{16}$ Documented history of the victim's alcohol consumption may have a serious impact on the outcome of the case. The case may not be presented in court if the victim who claimed to have been assaulted had been drinking, because the credibility of the evidence given by such a victim will be doubted in court. ${ }^{17}$

Further, in Pistorius v. The State (253/2013) [2014] ZASCA 47 (1 April 2014), $\operatorname{Dr}$ ' $N$ ', the medical doctor who treated the complainant, gave the following testimony (at Paragraphs [9], $[10]$ and [11]). ${ }^{14}$

The state then called $\mathrm{Dr}^{\prime} \mathrm{N}^{\prime}$, the medical doctor who treated the complainant. I hasten to state that his evidence was left unchallenged. Essentially, $\mathrm{Dr}^{\prime} \mathrm{N}^{\prime}$ confirmed that he is a qualified medical doctor with three degrees and that he examined the complainant on 27 December 2007. He described the injuries he observed on the complainant as huge haematomas with severe or gross oedema at several and multiple locations on the back. These locations were at the level of the scapula of the right hand. Furthermore, he described a haematoma - a large collection of blood - at the site of the injury.

Dr ' $N$ ' testified further that he observed weals on the complainant's upper back at almost the level of the shoulder but more medial. He described a weal as similar to when a person has been dragged with his face or his naked flesh on the ground, leaving areas slightly open, others dark with blood, others completely closed and swollen with the interstitial fluid. Importantly, he elaborated further that contusions are areas where a person has been struck by some blunt force as opposed to a sharp object like a knife.

Commenting on the possible weapons which could have caused the injuries on the appellant, $\mathrm{Dr}^{\prime} \mathrm{N}$ ' opined that it could be a knobkerrie or sjambok or a pipe or anything which will not perforate or cause the skin to open. Although he was unable to state with precision what object was used to assault the complainant, he opined that it was a blunt and not a sharp object.

During the examination of an assault victim, accurately defining a wound or injury is done by trying to ascertain the type of damage caused by the application of mechanical force to the skin/body. ${ }^{18}$ Data collected by this study show that the majority of the participants reported that they were able to accurately identify common skin injuries (bruises, abrasion, lacerations and incised wounds), but only $38.3 \%$ and $54 \%$ of participants respectively reported always measuring and documenting the shapes of the wounds found during the examination (see Table 3 ). The accurate description and measurement of wounds or injuries found at examination are essential in medico-legal proceedings, as this aids accurate identification of the weapon of assault or the cause of the injury. ${ }^{18}$ 
Furthermore, in Pistorius v. The State (253/2013) [2014] ZASCA 47 (1 April 2014), the court clerk documented the following (at Paragraph [12]). ${ }^{14}$

\section{Dr'N'remained firm and unshaken under cross-examination.}

This study found that $66.7 \%$ of the participants had some degree of undergraduate training on handling assault cases, while only $26.8 \%$ reported having had undergraduate training on completing the J88 for assault cases. This inadequate undergraduate training on medico-legal documentation of assault cases could create a sense of insecurity in less experienced CSDs, leading to them feeling intimidated in the court environment, and may result in reluctance among medical practitioners to become involved as court witnesses. ${ }^{6}$ This necessitates a new curriculum for clinical forensic medicine in the $\mathrm{MBChB}$ programme, to address the gap in knowledge and skills of medical graduates working on medico-legal cases.

\section{Conclusion}

The courts rely heavily on medico-legal documentation in cases of criminal prosecution. The burden of proof in criminal cases is beyond a reasonable doubt and that is a heavy burden indeed. Any substantial uncertainties or flaws in any of the components of the prosecutor's case, including poor observations and/or notes made by a medical practitioner, may make it impossible to reach the certainty necessary to assure a conviction. Using CSDs as a focal group, this study has revealed an important gap in knowledge of CSDs regarding the practice of clinical forensic medicine. It would be beneficial to direct a new curriculum for clinical forensic medicine to address the shortcomings of the undergraduate medical training programmes.

Funding - This work was supported by the Health and Welfare Sector Education and Training Authority (HWSETA) of South Africa [MOU HWSETA/UFS 2016/2017].

Conflict of interest - All authors declare that there was no conflict of interest.

\section{ORCID}

\section{AO Adefuye (iD http://orcid.org/0000-0003-2380-1487}

\section{References}

1. Milton J. South African criminal law and procedure: common-law crimes, vol. 2, 3rd edn. Wetton, Cape Town: Juta and Company Ltd; 1996.pp. 406-407.

2. Müller K, Saayman G. Clinical forensic medicine: completing the form j88-what to do and what not to do. S Afr Fam Pract. 2011; 45(8):39-43.
3. Norman R, Schneider M, Bradshaw D, et al. Interpersonal violence: an important risk factor for disease and injury in South Africa. Population Health Metrics. 2010;8(1):695. https://doi.org/10.1186/1478-7954-8-32

4. South African Police Service (SAPS). Crime statistics 2015/2016. Pretoria: SAPS Corporate Communications.

5. Kotzé JM, Brits H, Botes B. Part 1: Medico-legal documentation South African Police Services forms, Department of Justice forms and patient information. S Afr Fam Pract. 2014;56(5):16-22.

6. Wells DL. Sexual assault practice: myths and mistakes. J Clin Forensic Med. 2006;13(4):189-93. https://doi.org/10.1016/j.jcfm.2006.02.012

7. Dolinak D, Matshes E, Lew EO. Forensic pathology: principles and practice. Oxford: Elsevier Science; 2005.p. 122-39.

8. Demombynes G, Özler B. Crime and local inequality in South Africa. Journal of Dev Econ. 2005;76(2):265-92. https://doi.org/10.1016/j. jdeveco.2003.12.015

9. Jewkes R, Levin J, Penn-Kekana L. Risk factors for domestic violence: findings from a South African cross-sectional study. Soc Sci Med. 2002;55(9):1603-17. https://doi.org/10.1016/S0277-9536(01)00294-5

10. Forgus S, Delva W, Hauptfleisch C, et al. Community v. noncommunity assault among adults in Khayelitsha: A case count and comparison of injury severity. S Afr Med J. 2014;104(4):299-301. https://doi.org/10.7196/SAMJ.7615

11. Abrahams $\mathrm{N}$, Jewkes $\mathrm{R}$, Martin LJ, et al. Forensic medicine in South Africa: Associations between medical practice and legal case progression and outcomes in female murders. PLoS ONE 2011;6(12): e28620. https://doi.org/10.1371/journal.pone.0028620

12. Saayman G, van Oosten FF. Forensic medicine in South Africa-time for change? Med Law 1994;13:129-132.

13. Hoctor S. General principles and specific offences: recent cases. S Afr J Crim Just. 2014, 27(1):63-71. Available from: https://journals.co.za/ content/ju_sajcj/27/1/EJC158112.

14. The supreme court of appeal of South Africa: Pistorius v The State. 2014.(253/13) [2014] ZASCA 47 (01 April 2014). Pretoria: The North Gauteng High Court. Available from: www.justice.gov.za/sca/ judgments/sca_2014/sca2014-047.pdf.

15. Jina $R$, Jewkes $R$, Christofides $N$, et al. Caring for survivors of sexual assault and rape: a training programme for health care providers in South Africa. Pretoria: Department of Health; 2008.

16. Collins JJ, Messerschmidt PM. Epidemiology of alcohol-related violence. Alcohol health and research world. 1993;17(2):93-100.

17. Greenwood P. I was violently attacked but my case was dropped because I had been drinking. 2016. The guardian [cited 2017 Apr 18]. Available from: https://www.theguardian.com/lifeandstyle/2016/ jan/18/i-was-violently-attacked-but-my-case-was-dropped-beendrinking.

18. Brouwer I, Burger L. Medico-legal importance of the correct interpretation of traumatic skin injuries: main article. CME: Your SA Journal of CPD 2006, 24(3):112-15.

Received: 04-05-2017 Accepted: 31-07-2017 